\title{
Thysanoptera disjunct distribution between western America and the Mediterranean with a new Psilothrips species (Thripidae) from Iran
}

\author{
Kambiz Minaei ${ }^{1}$, Laurence Mound ${ }^{2}$ \\ 1 Department of Plant Protection, College of Agriculture, Shiraz University, Shiraz, Iran \\ 2 Australian National Insect Collection, CSIRO, PO Box 1700, Canberra, ACT 2601
}

http://zoobank.org/96E838D7-137A-4109-A9A1-C2864E39F7A1

Corresponding author: Kambiz Minaei (kminaei@shirazu.ac.ir)

Received 7 September 2014

Accepted 9 December 2014

Published 6 February 2015

Academic editor:

Dominique Zimmermann

\section{Key Words}

disjunct distribution

North America

Mediterranean

new species

thrips

\begin{abstract}
The genus Psilothrips Hood, 1927 is one of several Thysanoptera taxa with a disjunct distribution between the west coast of North America and the Mediterranean. Despite being considered a member of the Anaphothrips genus-group, two species of Psilothrips have long pronotal posteroangular setae, thus a revised generic diagnosis is provided. One new species, $P$. zygophylli sp.n. is described from Iran, P. indicus Bhatti, 1967 is proposed as a new synonym of $P$. bimaculatus (Priesner, 1932), and a key is provided to the five recognized species.
\end{abstract}

\section{Introduction}

More than 100 of the 235 genera of the Thysanoptera sub-family Thripinae each include only a single species (ThripsWiki 2014), usually known from a single locality. In contrast, only three genera each include more than 100 species, Frankliniella Karny, 1910, Scirtothrips Shull, 1909 and Thrips Linnaeus, 1758 and each of these genera is found worldwide, and thus equally uninformative about biogeographic relationships. The genus considered in this paper, Psilothrips Hood, 1927, is one of the smaller genera. It is of interest because it shows a remarkable disjunct distribution between Western America and Mediterranean countries. Due to incorrect observations based on poorly prepared slide-mounted specimens, and despite a recent critical study (Bhatti and de Borbon 2008), the available literature for Psilothrips is confusing and its relationships are not clearly defined.
The objectives of this paper are to clarify the generic diagnosis, to describe a new species from Iran, and to suggest a new synonymy for a species recorded from India and China.

\section{Material and methods}

The specimens of new species described in this paper were collected into $95 \%$ ethanol, and subsequently mounted onto slides in Canada balsam using a form of the protocol given in ThripsWiki (2014). The photomicrographs (except Fig. 10) were prepared using a Leica DM2500 microscope using D.I.C. illumination and Automontage imaging software, and line drawings were sketched using a drawing tube attachment to Zeiss Standard 20 microscope. The measurements as well as Fig. 10 were obtained using a Motic BA310 
microscope with attached camera. Terminology follows zur Strassen (2003) and Hoddle et al. (2014).

The following collection acronyms are used for the institutions cited in this paper:

ANIC Australian National Insect Collection, Canberra. BMNH Natural History Museum, London.

PPSU Department of Plant Protection, College of Agriculture, Shiraz University, Shiraz.

SMF Senckenberg Museum, Frankfurt.

The holotype and a male paratype have been deposited in BMNH. Most other specimens listed in this paper are deposited in PPSU, and a few in the ANIC.

\section{Results}

\section{Psilothrips Hood, 1927}

Psilothrips Hood, 1927: 198. Type species P. pardalotus Hood, 1927, by monotypy.

Remarks. Members of this genus can be distinguished from other Thripinae by the lack of a comb of microtrichia on the posterior margin of tergite VIII, and the presence of a particularly long pair of setae arising in a unique position on the antecostal ridges of tergites IIIVII (Figs 11, 13). Only one other genus shares these two character states, Apsilothrips Bhatti \& de Borbon, 2008 from western Argentina (Mendoza and Jujuy). The single species placed in that genus could equally well be interpreted as an unusual species of Psilothrips, but is weakly distinguished by the presence of small cilia on the anterior margin of the fore wing and complete absence of sternal discal setae. In contrast, other Thripinae taxa in which the median tergal setae are unusually long have these setae arising just posterior to the antecostal ridge; they also usually have a comb on tergite VIII, and cilia present on the anterior margin of the fore wing. A generic definition of Psilothrips was provided by O'Neill (1960), but that failed to mention several important character states, including the number of ocellar setae, the presence of six prominently pigmented facets ventrally on each compound eye, and the presence of a prominent spinula on both the meso and metafurca. The number of ocellar setae is particularly important because of the failure of earlier workers to note the presence of ocellar setae pair I in front of the first ocellus, including O'Neill's failure to illustrate these setae (see her Fig. 1/6). This led Bhatti (1967) to refer to an "additional" pair of anteocellar setae when describing $P$. indicus as a new species. This pair of setae is often very small, and is difficult to see due to the curvature of the head except when a specimen is very well cleared or the head crushed (Figs 1,2).

Generic diagnosis. Macropterous Thripinae. Antennae 8-segmented (Fig. 9), segment I with no dorso-apical setae, II with no long setae, sense cones on III-IV forked, III-VI with rows of microtrichia. Head transverse, with 3 pairs of ocellar setae, pair III near anterior margins of triangle (Figs 1,2); maxillary palps 2-segmented; compound eyes with 6 pigmented facets (Fig. 2). Pronotum transverse (Figs 3, 4, 5, 6), weakly sculptured, discal setae small; with 4 pairs of posteromarginal setae, of which one posteroangular pair sometimes longer than other pairs. Meso- and metafurca with spinula. Mesonotal anterior campaniform sensilla absent, median pair of setae distant from posterior margin. Metanotal sculpture irregularly reticulate, median setae arise medially; no campaniform sensilla (Figs 6, 7, 8). Tarsi 2-segmented. Fore wing costa with setae but no cilia (Fig. 10); first vein with 3 widely spaced setae on distal half; second vein with continuous, widely spaced, row of setae; clavus with 4 veinal setae and one discal seta; posterior fringe straight. Tergites with weak transverse reticulation, posterolaterally these lines bear small microtrichia; II-VIII with setae S1 (median pair) elongate (Figs 11, 12, 13), on III-VII arising on antecostal ridge; V-VII with setae S2 unusually elongate, almost as long as $\mathrm{S} 1$; tergites without ctenidia, VIII with no posteromarginal comb; tergite IX with one pair of campaniform sensilla (Fig. 12), without discal microtrichia (except $P$. priesneri), $\mathrm{X}$ with no median split (Fig. 12); pleurotergites with or without discal setae; sternites III-VII with 3 pairs of marginal setae (lateral pair on VII sometimes absent), discal setae varying in number from zero to eight. Male with sternal pore plates present or absent.

\section{Key to species of Psilothrips}

1 Pronotum with 1 pair of posteroangular setae as long as, or longer than, width of antennal segment II (Figs 5, 6); pleu. rotergal discal setae absent. Pronotum with no elongate setae, posteroangular setae less than 0.5 times as long as width of antennal segment II (Figs 3, 4); pleurotergal discal setae present or absent.

2 Metanotum posterior third with concentric sculpture lines (Fig. 6); major setae on pronotum setiform; western USA ... ...pardalotus

- Metanotum posterior third with equiangular reticulation (Fig. 8); major setae on pronotum longitudinally grooved; Iran... zygophylli sp.n.

3 Metanotum posterior third with many complex markings within each reticle (Fig. 7); tergite IX anterior third with prominent transverse band of microtrichia (Fig. 12); western USA ..... priesneri 

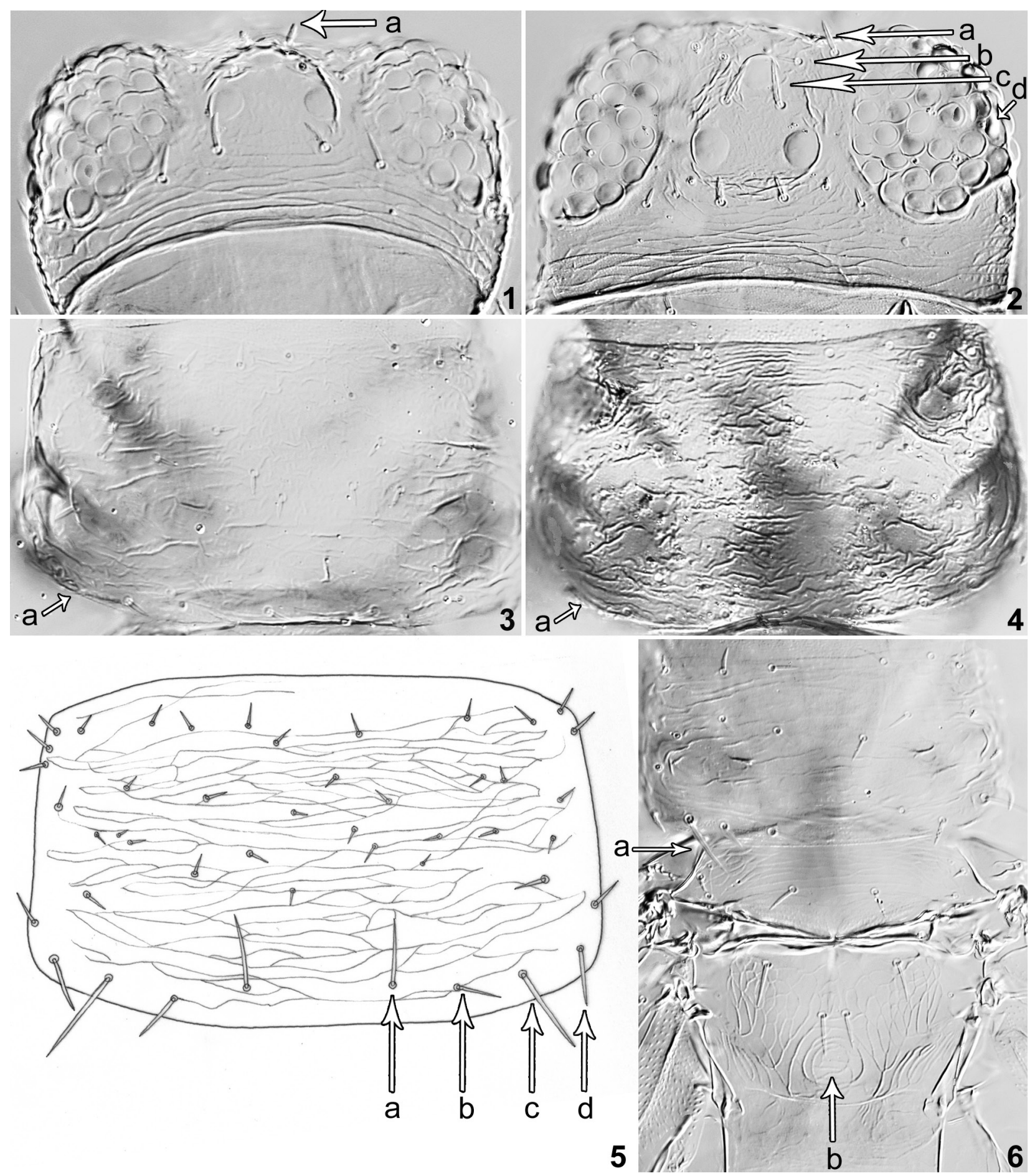

Figures 1-6. Psilothrips spp: Head (1) P. pardalotus; female (a: ocellar setae I) (2) P. zygophylli; paratype (a, b, c: ocellar setae I-III; d: pigmented facet). Pronotum (3) P. bimaculatus; female (a: no elongate posteroangular setae) (4) P. priesneri; female (a: no elongate posteroangular setae) (5) P. zygophylli; holotype (a: S1, b: S2, c: S3, d: S4). Pro, meso and metanotum (6) P. pardalotus; female (a: posteroangular setae, b: metanotal sculpture).

- Metanotal reticles with few or no internal markings; tergite IX with no prominent microtrichia.

4 Head and body uniformly brown (in life with bright red internal pigment); macropterae and micropterae; Canary Is. lands..... minutus

- Head and pronotum yellow with brown areas, tergites II-VII yellow posterolaterally (in life with orange pigment in ptero. thorax); only macropterae known; Morocco, Egypt, Yemen, Israel, India, China...... bimaculatus 


\section{Psilothrips bimaculatus (Priesner, 1932)}

Fig. 3

Thamnothrips bimaculatus Priesner, 1932: 3. Psilothrips indicus Bhatti, 1967: 12. Syn.n.

Remarks. Widespread in southern Mediterranean countries, from Morocco to Israel and Yemen, also in Iran from siris trees (Albizia sp., Fabaceae) in Khozestan Province (Alavi and Mohiseni 2002), this species is here interpreted to include records from India and central China. The type specimens of $P$. indicus, three females collected in Delhi on Ipomoea carnea (Convolvulaceae), are not available for study but are presumably in the "J.S. Bhatti Private collection" (Bhatti and de Borbon 2008). The proposed new synonymy is based on the original description, together with two females from Ningxia, China, collected from Lycium halimifolium (Solanaceae), 20.VII.1980, and identified as $P$. indicus by Han Yun-fa (in BMNH and SMF). These two females have been compared with females from Morocco, Egypt, Israel and Yemen. The colour, as described by Bhatti (1967) is distinctive, with abdominal tergites II-VII sharply paler posterolaterally, and the metanotal equiangular reticulations with few or no internal markings. This species, under the name of $P$. indicus, has been considered a pest on Chinese wolfberry (Lycium spp.) in China (Li et al. 2012).

\section{Psilothrips minutus zur Strassen, 1965}

Psilothrips minutus zur Strassen, 1965: 27.

Remarks. Known only from the Canary Islands on Suaeda fruticosa, this species is unusually dark, and is the only member of the genus for which micropterous individuals are known. None of the available specimens are suitably cleared, but pleurotergal discal setae are not discernable. The tergal antecostal ridge is weaker in this species than among the other members of this genus, and the micropterae have the median tergal setae irregular in size and on some tergites arising posterior to the antecostal ridge.

\section{Psilothrips pardalotus Hood, 1927}

Figs 1, 6, 11

\section{Psilothrips pardalotus Hood, 1927: 198.}

Remarks. As recognised by O'Neill (1960), the metanotal sculpture of this species is diagnostic (Fig. 6), and the major pronotal posteroangular setae are about $30 \mu \mathrm{m}$ long. The species is recorded from Arizona, California, Idaho, Nevada, New Mexico, Texas, and Utah, and appears to be associated with Sarcobatus vermiculatus. In contrast to $P$. priesneri, the abdominal pleurotergites lack discal setae, and tergite IX lacks discal microtrichia.

\section{Psilothrips priesneri (Moulton, 1926)}

Figs 4, 7, 12

Anaphothrips priesneri Moulton, 1926: 123.

Remarks. The metanotal reticulation of this species, with extensive markings inside each reticle as illustrated by O'Neill (1960), is diagnostic for this species (Fig. 7). The pleurotergites bear several discal setae, and tergite IX has a distinctive transverse band of microtrichia (Fig. 12). This species has been recorded in western USA from Arizona, California, and Texas.

\section{Psilothrips zygophylli sp. n.}

http://zoobank.org/203380BE-3F22-4BF2-83C0-073E8EFF8D23

Figs 2, 5, 8, 9, 10, 13

Female macroptera. Body yellow to light brown, antennal segments I, III and IV pale, remaining segments shaded; head and pronotum with posterior margins weakly shaded; pterothorax light brown medially, including metascutellum; abdominal tergites I-VIII yellow laterally but with light brown patch medially; fore wings weakly shaded.

With the character states in the generic diagnosis; antennal segments slender (Fig. 9) with reduced microtrichia. Head weakly reticulate in basal third, ocellar setae III on anterior margins of ocellar triangle (Fig. 2).

Pronotum with irregular transverse sculpture lines; 4 pairs of posteromarginal setae, S1 and S3 longer than S2 and S4 (Fig. 5). Metanotum with equiangular reticulation on posterior half, median setae often asymmetric in position (Fig. 8). Fore wing relatively broad; first vein with two setae distally, second vein with about 11 setae (Fig. 10); apex with small sub-apical lobe bearing many long microtrichia ventrally. Abdominal tergites with transverse reticulation medially (Fig. 13), setae S2 slightly shorter than setae S1; tergites IV-VI with striate sculpture laterally bearing a few short microtrichia; sternites III-VII with about eight discal setae.

Measurements (holotype female; measurements in micrometer). Table 1.

Male macroptera. Similar to female but paler. Tergite IX without any processes or stout setae; sternites apparently without pore plates.

Table 1. Measurements of various parts of holotype female and paratype male in micometer.

\begin{tabular}{l|l|l}
\hline Feature & Female & Male \\
\hline Body distended length & 1440 & 800 \\
\hline Head length (width) & $124(212)$ & $82(140)$ \\
\hline Pronotum length (width) & $133(240)$ & $93(142)$ \\
\hline Posteroangular setae & 36 & 24 \\
\hline Fore wing length (median width) & $1048(115)$ & $567(50)$ \\
\hline Tergite II S1 setae & 48 & - \\
\hline Ovipositor length & 240 & - \\
\hline Antennal segments III-VIII length & $46,43,40,56,18,21$ & $36,35,34,42,15,19$ \\
\hline & &
\end{tabular}



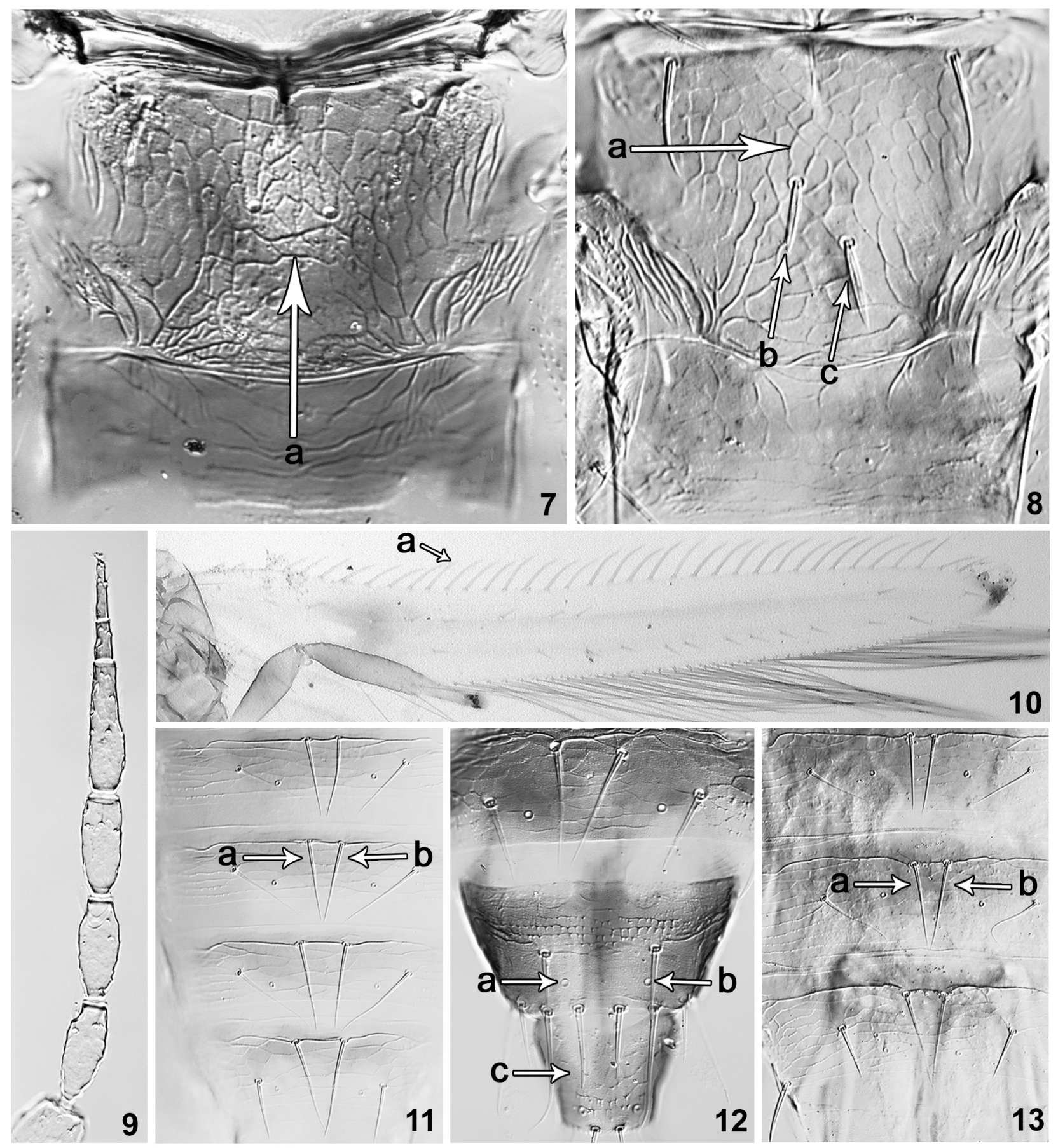

Figures 7-13. Metanotum (7) P. priesneri; female (a: metanotal sculpture) (8) P. zygophylli; paratype (a: metanotal sculpture; b, c: median setae). Antenna (segments II-VIII) (9) P. zygophylli; paratype. Forewing (10) P. zygophylli; paratype (a: setae). Abdominal tergites (11) P. pardalotus (V-VIII); female (a, b: median tergal setae) (12) P. priesneri (VIII-X); female (a, b: campaniform sensilla; c: tergite $\mathrm{X}$ without split) (13) P. zygophylli (VI-VIII); paratype (a, b: median tergal setae).

Measurements (paratype male; measurements in micrometer). Table 1.

Specimens examined (slide-mounted). Holotype female, IRAN, Fars Province, Sarvestan, $100 \mathrm{~km}$ west of Shiraz, from leaves of Zygophyllum sp. (Zygophyllaceae), 17.IV.2014 (KM 1151) (in BMNH).

Paratypes: 7 females, taken with the holotype; 17 females, 6 males, 4 larvae, IRAN, Fars Province, Sarves- tan, from leaves of Zygophyllum sp., 9.V.2014 (KM 1185) (in PPSU), 2 females, 1 male, 1 larva, IRAN, Fars Province, Sarvestan, from leaves of Zygophyllum sp. (in ANIC).

Etymology. This species is named after the genus of plant from which it was collected.

Comments. This new species shares many character states with the North American species P. pardalotus. 
It differs in the form of the metanotal sculpture, longer major setae on the head and pronotum which are more prominently longitudinally grooved, shorter setae $\mathrm{S} 2$ on the abdominal tergites, and more slender antennae.

\section{Discussion}

\section{Disjunct distribution in Thysanoptera}

This paper considers the interesting zoogeographical distribution of the five species now recognised in the Thripinae genus Psilothrips. Two of the species are from the drier areas of western North America, whereas three are from similar low rainfall areas across North Africa and Asia. Among Thysanoptera, a similar distribution pattern is found in the genus Orothrips Moulton, 1907 of the family Aeolothripidae, with three species from western North America and one from the Mediterranean region (Marullo and Mound 1993), and at genus level in the family Stenurothripidae that comprises two monobasic genera in western USA and one small genus in the Mediterranean region (Mound 1983, Mound and Marullo 1999). Similarly the genus Ankothrips Crawford, 1909 in the family Melanthripidae shows remarkable disjunction, with seven species from western North America, one from Namibia in south-west Africa, and five from the western Palaearctic including one recently described from Iran (Minaei et al. 2012). Regardless of any possible historical component involved in such disjunctions, for Psilothrips the distribution is probably related to ecological conditions and the available flora. Available records of plants from which Psilothrips adults have been collected include many that are typical of semi-arid areas: Amaranthus (Amaranthaceae), Allenrolfea, Atriplex, Sarcobatus and Suaeda (Chenopodiaceae), Calotropis (Asclepiadaceae), Lycium (Solanaceae), and Nitraria and Zygophyllum (Zygophyllaceae).

\section{Pronotal setal lengths and Thysanoptera systematic relationships}

The new species described above emphasizes one of the problems involved in assessing systematic relationships among Thysanoptera. Psilothrips is presumed to be a member of the Anaphothrips group of genera, in which species do not bear any long setae on the pronotum (Bhatti 1978, Mound and Masumoto 2009). Certainly three of the species are essentially "anaphothripoid", but two have prominent posteroangular setae on the pronotum and, if considered in isolation, might well be considered unrelated. Although setal lengths have traditionally been considered important in assessing relationships among the taxa within several families, there is increasing evidence that reduction in setal length (i.e. loss of long setae) occurred convergently in widely unrelated genera (Mound and Palmer 1981, Pereyra and Mound 2009, Minaei et al. 2012). In contrast, it appears that within Psilothrips one or more reversions from an Anaphothrips-like condition to long pronotal posteroangular setae have taken place.

\section{Acknowledgements}

Open access to this paper was sponsored by the Museum für Naturkunde, Berlin. Andrea Hastenpflug-Vesmanis at the Senckenberg Museum, Frankfurt (SMF), and Paul Brown at the Natural History Museum, London $(\mathrm{BMNH})$, kindly provided specimens on loan from their collections. The manuscript was improved through the advice and criticisms provided by Mag. Dominique Zimmermann, editor-in-chief of the Deutsche Entomologische Zeitschrift as well as two anonymous referees.

\section{Refernces}

Alavi J, Mohiseni AA (2002) Psilothrips bimaculatus (Priesner) a new record for Thysanoptera fauna of Iran. Proceedings of the $15^{\text {th }}$ Iranian Plant Protection Congress, Razi University of Kermanshah, Vol. I, 183-184.

Bhatti JS (1967) Thysanoptera Nova Indica. Published by the author. Delhi, $24 \mathrm{pp}$.

Bhatti JS (1978) Systematics of Anaphothrips Uzel 1895 sensu latu and some related genera. Senckenbergiana biologica 59: 85-114.

Bhatti JS, de Borbon CM (2008) A new genus and species of thrips related to Psilothrips Hood 1927 living on the South American saltbush, Atriplex lampa Gill. ex Moq. (Chenopodiaceae), in Argentina (Terebrantia: Thripidae). Thrips 6: 1-43.

Hoddle MS, Mound LA, Paris D (2014) Thrips of California 2012. http://keys.lucidcentral.org/keys/v3/thrips_of_california/Thrips_of_ California.html [7.ix.2014]

Hood JD (1927) New western Thysanoptera. Proceedings of the Biological Society of Washington 40: 197-204.

Li X, He J, Cao Y (2012) Occurrence and control of Psilothrips indicus Bhatti. Plant Diseases and Pest 3: 19-20, 34.

Minaei K, Haftbaradaran F, Mound LA (2012) A new Ankothrips species (Thysanoptera: Melanthripidae) from Iran with unusually short setae. Zootaxa 3552: 37-42. http://mapress.com/zootaxa/2012/f/ zt03552p042.pdf

Marullo R, Mound LA (1993) Discontinuous distribution and systematic relationships of the genus Orothrips (Thysanoptera: Aeolothripidae) and related taxa in Mediterranean climates. Journal of the New York Entomological Society 101: 561-566.

Moulton D (1926) New American Thysanoptera. Transactions of the American Entomological Society 52: 119-128.

Mound LA (1983) Natural and disrupted patterns of geographical distribution in Thysanoptera (Insecta). Journal of Biogeography 10: 119-133. doi: 10.2307/2844623

Mound LA, Marullo R (1999) Two new basal-clade Thysanoptera from California with Old World affinities. Journal of the New York Entomological Society 106: 81-94.

Mound LA, Masumoto M (2009) Australian Thripinae of the Anaphothrips genus-group (Thysanoptera), with three new genera 
and thirty-three new species. Zootaxa 2042: 1-76. http://www.mapress.com/zootaxa/2009/f/zt02042p076.pdf

Mound LA, Palmer JM (1981) Phylogenetic relationships between some genera of Thripidae (Thysanoptera). Entomologica Scandinavica $15: 153-17$.

O’Neill K (1960) The taxonomy of Psilothrips Hood (Thysanoptera: Thripidae). Proceedings of the Entomological Society of Washington 62: 87-95.

Pereyra V, Mound LA (2009) Phylogenetic relationships within the genus Cranothrips (Thysanoptera, Melanthripidae) with consideration of host associations and disjunct distributions within the family. Systematic Entomology 34: 151-161. doi: 10.1111/j.1365-3113.2008.00445.x
Priesner H (1932) Contribution towards a knowledge of the Thysanoptera of Egypt, V. Bulletin de la Societé Royale Entomologique d'Égypte 16: 2-12.

ThripsWiki (2014) ThripsWiki - providing information on the World's thrips. http://thrips.info/wiki/Main_Page [7.ix.2014]

zur Strassen R (1965) Einige neue terebrante Thysanopteren-Arten von den Kanarischen Inseln (Ins., Thysanoptera). Commentationes biologicae: Societas Scientiarum Fennica 28: 3-41.

zur Strassen R (2003) Die terebranten Thysanopteren Europas und des Mittelmeer-Gebietes. Die Tierwelt Deutschlands 74: 1-271. 